\title{
História, memória e esquecimento: Implicações políticas
}

History, memory and forgetting: Political implications

Histoire, mémoire et oubli : implications politiques

Maria Paula Nascimento Araújo e Myrian Sepúlveda dos Santos

\section{OpenEdition}

\section{Journals}

Edição electrónica

URL: http://journals.openedition.org/rccs/728

DOI: $10.4000 /$ rccs. 728

ISSN: 2182-7435

\section{Editora}

Centro de Estudos Sociais da Universidade de Coimbra

Edição impressa

Data de publição: 1 Dezembro 2007

Paginação: 95-111

ISSN: 0254-1106

\section{Refêrencia eletrónica}

Maria Paula Nascimento Araújo e Myrian Sepúlveda dos Santos, «História, memória e esquecimento: Implicações políticas », Revista Crítica de Ciências Sociais [Online], 79 | 2007, colocado online no dia 01 outubro 2012, criado a 01 maio 2019. URL : http://journals.openedition.org/rccs/728 ; DOI : 10.4000/ rccs. 728 


\section{MARIA PAULA NASCIMENTO ARAÚJO MYRIAN SEPÚLVEDA DOS SANTOS}

\section{História, memória e esquecimento: Implicações políticas}

Pesquisadores têm colocado em questão a recuperação de situações traumáticas como as que ocorreram no Holocausto, no bombardeio a Hiroshima, na guerra do Vietnam ou nos massacres fratricidas da lugoslávia. Embora algumas contribuiç̧ões clássicas tenham assinalado aspectos importantes relativos à história e memória, há várias formas de lidar com o passado e todas elas envolvem interesse, poder e exclusões. A política da justa memória a ser realizada sobre crimes cometidos passados, debate que vem sendo travado não só em diversas áreas acadêmicas, como na sociedade em geral, depende de processos seletivos, bem como de elementos que excedem o escopo da razão humana. É preciso encontrar o equilíbrio entre a obsessão pelo passado e as tentativas de imposição do esquecimento. Nosso intuito, portanto, é o expandir o conhecimento sobre história, memória e esquecimento, ressaltando limites, bem como implicações éticas e morais.

\section{Introdução}

Este artigo tem como objetivo investigar os impasses entre memória e esquecimento que estão presentes em debates sobre a preservação e divulgação de arquivos relacionados a conflitos, guerras e períodos de opressão política. O debate sobre a justiça a ser realizada sobre crimes cometidos passados, que vem sendo travado não só em diversas áreas acadêmicas, como na sociedade em geral, embora não dependa apenas de documentos e testemunhos, tem neles um grande aliado. Nem sempre, entretanto, sociedades optam pela lembrança. Nosso intuito, evidentemente, não é o de esgotar o debate em torno do lembrar e do esquecer, mas, pelo contrário, expandir o conhecimento sobre estes termos, o que implica em estabelecer também seus limites.

A primeira parte deste artigo terá como base os trabalhos de sociólogos, historiadores e filósofos, como Maurice Halbwachs, Pierre Nora e Paul Ricoeur, sobre memória coletiva. Narrativas históricas que presidem a organização de arquivos, coleções e museus nos lembram daquilo que é passado, 
ou seja, daquilo que não está mais presente entre nós. Ainda assim, elas não proporcionam a revelação de uma verdade absoluta; elas nos levam ao processo de constituição das coleções ocorrido a partir de interesses conflitantes. A memória opera a partir de um processo seletivo e pode se tornar uma arma política para as vítimas de guerras e genocídios, em que o esquecimento estabeleceu sua hegemonia.

A segunda parte deste artigo lidará com casos em que não há apenas um processo seletivo entre o que deve ser lembrado. Autores como Georges Bataille e Max Scheler nos apresentam situações em que indivíduos e comunidades, ao se voltarem para o passado, podem ser incapazes de transmitir o aprendizado oriundo da experiência e da dor. A memória não obedece apenas à razão porque ela também está relacionada, por um lado, a tradições herdadas, que fazem parte de nossas identidades e que não respondem a nosso controle, e, por outro, a sentimentos profundos, como amor, ódio, humilhação, dor e ressentimento, que surgem independentemente de nossas vontades.

Como resultado destes desafios, procuraremos mostrar, na terceira parte deste artigo, diversas situações históricas em que alternativas se constroem com o intuito de superar o distanciamento entre passado e presente e estabelecer uma agenda, em que a lembrança se vincula à possibilidade do esquecimento.

\section{O processo seletivo da memória}

Maurice Halbwachs foi o primeiro sociólogo a resgatar o tema da memória para o campo das interações sociais. ${ }^{1}$ Rejeitando a idéia corrente em sua época de que a memória seria o resultado da impressão de eventos reais na mente humana, ele estabeleceu a tese de que os homens tecem suas memória a partir das diversas formas de interação que mantêm com outros indivíduos. Assim sendo, determinadas lembranças são reiteradas no seio de famílias, outras entre os operários que trabalham em uma fábrica e assim por diante. Como os indivíduos não pertencem apenas a um grupo e se inserem em múltiplas relações sociais, as diferenças individuais de cada memória expressam o resultado da trajetória de cada um ao longo de sua vida. A memória individual revela apenas a complexidade das interações sociais vivenciada por cada um.

\footnotetext{
${ }^{1}$ Maurice Halbwachs estabeleceu os principais argumentos teóricos de defesa do caráter coletivo da memória coletiva em duas obras que hoje se tornaram referências obrigatórias ao tema, Os quadros sociais da memória (1925) e A memória coletiva, esta última publicada após sua morte (1950).
} 
O grande mérito do trabalho de Halbwachs, portanto, é mostrar que a memória individual não pode ser distanciada das memórias coletivas. Não é o indivíduo isoladamente que tem o controle do resgate sobre o passado. A memória é constituída por indivíduos em interação, por grupos sociais, sendo as lembranças individuais resultado desse processo. Ainda que o indivíduo pense que sua memória é estritamente pessoal, uma vez que ela pode resgatar acontecimentos nos quais só ele esteve envolvido ou fatos e objetos que só ele presenciou e viu, ela é coletiva, pois o indivíduo ainda que esteja só é o resultado das interações sociais. Ele vê o mundo através de construções coletivas como a linguagem. Dois indivíduos, de tradições culturais distintas, ao se perderem em um mesmo deserto trarão lembranças, descrições e sentimentos diferenciados de suas experiências. Estas não são estritamente individuais, pois, como afirma Halbwachs, o indivíduo nunca está só.

Contudo, ao tornar a memória objeto das ciências sociais, Halbwachs reitera a tese durkheimiana sobre a preponderância da consciência coletiva sobre o indivíduo. A ênfase dada por Halbwachs às representações coletivas foi contrabalançada no plano teórico por aqueles que investigaram a participação dos agentes sociais nos processos interativos. A memória, a tradição e a história são pensadas por alguns autores como representações coletivas que são constituídas ativamente por atores sociais. A coletânea de artigos organizada por David Middleton e Derek Edwards consolidou a abordagem interacionista nos estudos sobre memória coletiva (Middleton e Edwards, 1990). Em que pese as diferenças, tanto o estudo dos quadros sociais da memória, por Halbwachs, como as abordagens interacionistas às memórias coletivas são capazes de nos mostrar que não há nem verdade histórica, nem memória espontânea.

Ciente das preocupações já delineadas, Nora organizou, na década de 80, uma coletânea em que os autores se voltaram para a investigação dos "lugares da memória" da nação francesa, ou seja, dos lugares simbólicos constituídos pela e constitutivos da nação francesa. Além disso, os objetos de estudo para Nora não são fontes documentais nem memórias individuais, mas testemunhos de uma outra era; investiga-se a formação de museus, arquivos, cemitérios, celebrações, coleções e assim por diante. Marcou ainda o debate sobre memória coletiva, a distinção feita por Nora entre história e memória (Nora, 1984). Na introdução que escreveu a sua coletânea, hoje uma referência obrigatória para os estudiosos do tema, Nora contrastou as abordagens ao passado. Segundo ele a história corresponde à aceleração moderna do tempo, o que faz com que perceba eventos como sendo efêmeros, transitórios e pertencentes a um tempo homogêneo. Nora apontou os limites desta historiografia, descrita por ele como sendo uma narrativa lógica e linear, vazia 
de conteúdo sobre o passado. Ao contrário da história, as memórias coletivas estariam ligadas a movimentos contínuos e lembranças transmitidas entre gerações. Não obstante, elas também têm limites à compreensão do passado, pois o indivíduo não tem consciência de que transforma o passado segundo sua própria percepção. A memória, individual ou coletiva, é vulnerável a usos e manipulações (Nora, 1984; Davis e Starn, 1989). Assim sendo, tanto a história como a memória teriam limites no acesso ao passado.

$\mathrm{Na}$ distinção que fez entre memória e história, Nora contextualizou as diferentes formas de ida ao passado. Mostrou que na modernidade as percepções de tempo e as narrativas históricas seguem os processos de aceleração do tempo. Walter Benjamin, em suas reflexões sobre a história, já apontava os limites da abordagem histórica que enumerava fatos e eventos ao longo de um tempo homogêneo. Benjamin percebeu que a transmissão de representações coletivas entre indivíduos ao longo do tempo e do espaço tornar-se-ia cada vez mais esparsa e descontínua (Benjamin, 1968). Outro autor que se destacou ao contextualizar as narrativas históricas foi o historiador alemão Reinhart Koselleck. Para ele, o tempo da modernidade aparece diferenciado pelo conceito de "novo", que torna cada momento único e independente dos que the antecederam. O mundo moderno distingue-se do velho porque é pleno de características singulares e por ser capaz de se abrir sempre para uma possibilidade de futuro. Este "tempo-futuro", independente da experiência cotidiana construída através dos séculos, traz consigo o corte entre presente e passado e o ostracismo de tudo o que ficou para trás (Koselleck, 1985).

A crença neste hiato entre presente e passado, bem como na reconstrução contínua do passado pelo presente, é levada ao extremo por autores que trabalham com o conceito de destradicionalização. Autores como Anthony Giddens (1990), Ulrich Beck et al. (1994) e Scott Lash (1998) são defensores da tese de que os indivíduos contemporâneos detêm uma grande autonomia em relação às tradições; eles seriam indivíduos desencaixados e livres para se engajarem em novas experiências. Caracterizam o momento atual pelo ritmo acelerado de transformação nas sociedades contemporâneas; a singularidade dos indivíduos caracterizar-se-ia pelo seu distanciamento de experiências coletivas anteriores. Diferentemente do pessimismo de Benjamin, eles acreditam que quanto mais instáveis e movediças sejam as interações sociais, mais peso ganha a ação do indivíduo, ou seja, sua capacidade de escolha e decisão. As narrativas históricas, nesse contexto, refletem um processo incessante de seleção e reconstrução de vestígios do passado. ${ }^{2}$ Portanto, para estes autores,

${ }_{2}^{2}$ Para uma crítica à noção de destradicionalização, ver Santos, 1998. 
tanto a história como a memória lidam com a descontinuidade do tempo moderno. Evidentemente, há autores que ainda acreditam na comunicação entre passado e presente. Paul Ricœur, filósofo francês, soube não só contextualizar, mas entrelaçar com maestria memória, história e esquecimento. Para o filósofo, a memória seria um trabalho contínuo sempre capaz de se sobrepor a processos estruturais pré-estabelecidos (Ricœur, 2000).

Nosso intuito, ao longo desse artigo, é mostrar que há uma diversidade importante entre os caminhos ao passado e que praticamente todos eles são permeados por tensões, conflitos e disputas. Memória, história e esquecimento são experiências necessárias, que nem se confundem, nem se complementam. Hoje nós nos encontramos muito distantes tanto da noção de história como registro fiel do passado, como da redução da memória a um tipo de reconstrução seletiva do passado. O passo fundamental a ser dado é perceber, portanto, que na reconstrução do passado nada há de natural.

A construção de arquivos, notação de dados, organização de eventos e celebrações são atividades da memória que cumprem papéis sociais fundamentais na sociedade em que vivemos. No que diz respeito à formação e preservação de arquivos relacionados a períodos de dominação e violência, em que direitos humanos são desrespeitados, há sempre uma luta política importante sendo travada a cada momento. Ao longo do século XX, a grande demanda dos que foram vítimas de governos totalitários e repressivos deu-se em torno de movimentos pelo resgate da memória. Os arquivos, artefatos e relatos do passado têm sido utilizados como provas de um passado que foi deliberadamente esquecido pelas versões oficiais da história. Procura-se lembrar tudo aquilo que foi deliberadamente colocado no limbo da história. A lembrança, contudo, está vinculada àqueles que têm o poder, pois são eles que decidem quais narrativas deverão ser lembradas, preservadas e divulgadas.

Nos anos 80, na América Latina, governos democráticos sucederam as ditaduras militares. Em diversos países, foram decretadas leis de anistia e do perdão que permitiram a reintegração dos antigos opositores ao regime, mas que também evitaram o julgamento dos que foram responsáveis por torturas e outros crimes bárbaros. Apenas nos últimos anos, os pactos de perdão e esquecimento formados começaram a ser revistos. Em 2006, pela primeira vez no Brasil, vítimas de seqüestro e tortura durante o regime militar, que tiveram suas vidas brutalmente mutiladas, questionaram a lei de Anistia, decretada em 1979. Também na Argentina, somente nos últimos

\footnotetext{
${ }^{3}$ O casal César Teles e Maria Amélia Teles, a irmã desta última, Criméia Almeida, e dois filhos do casal, Janaína e Édson, impetraram uma ação judicial por danos morais e à integridade física contra um agente dos órgãos de segurança dos anos 70, Carlos Alberto Brilhante Ustra.
} 
anos as chamadas leis do perdão foram colocadas em questão, passando a Justiça a rever os crimes perpetrados por funcionários públicos ligados à ditadura militar. ${ }^{4} \mathrm{O}$ mesmo tem acontecido no Uruguai e Chile. ${ }^{5}$

Os diversos debates sobre reconciliação e verdade na África do Sul pós-apartheid também podem ser compreendidos como resultado de um tênue acordo político que procura ser estabelecido. As forças que estão contidas em lembranças são tão grandes e complexas que mesmo quando a oposição assume o poder político, nem sempre ela pode promover a lembrança do passado que foi reprimida. Em meio ao ódio e ressentimento acumulados ao longo de muitas gerações, o que pode ser lembrado? Como instrumentos de poder, memória e esquecimento têm sido utilizados por governos diversos, sejam eles totalitários ou democráticos, que têm o objetivo de alcançar controle político sobre forças antagônicas. O esquecimento, portanto, também tem sido uma estratégia política utilizada por governos democráticos em determinados períodos. Esses exemplos são importantes porque eles nos mostram que as associações entre memória, autonomia e liberdade, por um lado, e esquecimento e autoritarismo, por outro, não podem ser generalizadas.

A atuação dos Estados Unidos na guerra do Vietnam ainda não foi devidamente debatida publicamente em fóruns globais. Podemos dizer que há muito a ser lembrado. O livro autobiográfico do então Secretário de Defesa, Robert McNamara (2006), deixa evidente que os muitos erros cometidos ainda não foram devidamente julgados. Aqueles que respaldaram as decisões de um massacre devastador da população civil vietnamita por meio de napalm, gases tóxicos e bombas em escala massiva ainda estão próximos ao poder. A cegueira moral que ainda prevalece nos dias de hoje em relação ao Vietnam pode estar associada, por um lado, à continuidade do poder dos Estados Unidos na esfera internacional, e, por outro, à falta de distanciamento da sociedade americana em relação aos crimes cometidos. É inegável, portanto, a importância dos arquivos e testemunhos para as diversas forças em confronto, bem como as implicações políticas destes nos embates políticos.

\footnotetext{
${ }^{4}$ Apesar do forte movimento das "Mães da Praça de Maio", apenas em 2005 a Argentina revogou as leis de ponto final e de obediência devida, também conhecidas como leis do perdão, que impediam processos contra os responsáveis por violação dos direitos humanos. Em 2006, a Justiça considerou inconstitucional o indulto ao ex-presidente Jorge Rafael Videla. No mesmo ano, condenou à prisão perpétua o ex-policial, Miguel Etchecolatz, 77 anos, por crimes cometidos durante a ditadura militar.

${ }_{5}^{5}$ No Uruguai, apenas em 2006, 21 anos após o restabelecimento da democracia, o Ministério Público pediu a abertura de processos contra militares e policiais responsáveis por crimes cometidos durante a ditadura militar.
} 


\section{Frente à impossibilidade de lembrar o passado}

Como dito inicialmente, nem tudo o que diz respeito ao passado é objeto de negociações no presente. Abordagens historiográficas mais recentes tornam a busca ao passado mais complexa do que o simples jogo de interesses travado no presente. Autores como Hayden White, ao abolirem a busca a uma presença originária, não lingüística, aproximaram todas as abordagens a tentativas de interpretação restritas ao domínio da linguagem. ${ }^{6}$ Relativiza-se com isso não só as narrativas sobre a natureza de um evento, mas também suas implicações políticas. Uma das características da historiografia contemporânea é a revisão sistemática que é feita sobre os conflitos políticos da era moderna. Na França, não só os grandes eventos relacionados à Revolução Francesa têm sido revisados, como a herança do governo Vichy é constantemente reinterpretada.

Há aqueles também que trabalham com a memória em situações de extrema agressividade e violência. Nesse caso, observa-se a incapacidade de resposta das vítimas, que, ao não serem capazes de compreender experiências vivenciadas e lhes dar significados, tornam-se incapazes de operar com suas memórias de forma seletiva. A memória, portanto, não pode ser reduzida a instrumento político; ela excede as tentativas de controle.

As tentativas de recuperar situações traumáticas como as que ocorreram no Holocausto, no bombardeio a Hiroshima, na guerra do Vietnam ou nos massacres fratricidas da Iugoslávia, têm criado o efeito perturbador de esvaziar o sentido de tragédia que estes eventos catastróficos implicaram no passado. Nas palavras de Georges Bataille, a revelação dos efeitos da bomba de Hiroshima tornou-se o oposto da revelação dos fatos (Bataille, 1995: 228-229). Ele quer dizer com isso que a representação humana desta catástrofe não é capaz de dar a exata dimensão do evento, mas tem o efeito perverso de tornar banal o que não é. Para ele, como o horror não tem palavras para se descrever, o sentimento do horror não pode ser o ponto de partida para a ação que procura descrever este horror (ibidem). A história que foi contada, ao trazer à tona uma explicação do que acontecera, cumpriu o papel de justificar e banir do imaginário coletivo a violência injustificada.

A possibilidade de representação da realidade é sempre um desafio. Podemos compreender que o horror não tem palavras para ser descrito, aqueles que tentam explicá-lo acabam por apagar qualquer possibilidade de encontro e reparação em relação à tragédia. Indivíduos obtêm refúgio no mundo da atividade, mas nem sempre eles resolvem os problemas rela-

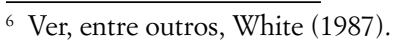


cionados à violência e ao sofrimento, que são componentes básicos da vida humana. Pesquisadores de diversos campos disciplinares têm se dedicado a estudar as possibilidades de reconstrução e explicação do trauma.

Freud e Lacan, cada um a seu modo, nos mostraram que indivíduos não têm total controle sobre suas memórias; elas tanto podem retornar reiteradamente sem serem desejadas, como desaparecer sem que haja a opção da lembrança. Para Freud, o trauma é uma conseqüência ou da natureza devastadora do evento ou do aparato psíquico do indivíduo, que pode não estar preparado para responder a determinados estímulos (Freud, 1955). Quando um estímulo muito forte nos atinge, nós não somos capazes de responder a estes estímulos. Este estímulo quebra nossas barreiras protetoras e passa a fazer parte de nosso próprio organismo, sem que nós possamos nos defender dele. A consciência reflexiva falha. Desta maneira, ele explica pesadelos que voltam reiteradamente fazendo com que indivíduos percam energia, sem poderem se defender deles. A agressão realizada no passado retorna em flashbacks, pesadelos e outros fenômenos similares; ela é a causa dos sintomas, ações repetitivas que visam diminuir o stress causado pela agressão inicial.

Além disso, as obras de Nietzsche e Scheler nos ajudam a compreender atitudes que ultrapassam qualquer limite moral a ser esperado de seres humanos. Memória e esquecimento também envolvem questões éticas e morais. Scheler, em seu estudo sobre o ressentimento, aponta como experiências profundas relacionadas ao sofrimento e à humilhação podem levar a um sentimento extremamente contagioso de vingança e rancor (Scheler e Frings, 1994). Ao relacionarmos uma experiência traumática à identidade do sujeito, podemos compreender que a atitude deste com seu passado não se volta apenas para o conhecimento do que foi deixado para trás. A lembrança não pode ser considerada apenas como um passado reconstruído. Ela pode levar o indivíduo a reviver uma experiência e evocar novos desejos e emoções, e estes podem ser extremamente negativos e auto-destruidores. A volta ao passado pode conter uma possibilidade de conhecimento, mas traz também uma renovação de sentimentos anteriormente reprimidos. Ainda que a representação seja possível, basta saber se ela é desejável, se ela é capaz de integrar o trauma em nossas vidas de modo articulado e não patológico.

O que responder, por exemplo, à questão levantada por Taussig, quando este denuncia a brutalidade com que os espanhóis dizimaram os ameríndios ao chegarem na América? O antropólogo argumenta corretamente que a conquista já se efetivara e não requeria tal violência (Taussig, 1986). Como compreender o Holocausto? Como explicar o massacre dos Tutsis em 
Rwanda? O que dizer da atitude dos sérvios em Kosovo? Por mais que historiadores procurem explicações para as barbáries cometidas, o excesso cometido parece sempre ficar além da compreensão lógica e racional.

Alguns pesquisadores acreditam que em caso de extrema violência pode haver uma relação direta entre evento e representação. Tal como Bataille, Friedländer também defende a tese de que a violência extrema possui característica única. A exterminação dos judeus não pode ser objeto de discussão teórica, ela foi um evento único e precisa ser gravado como tal. Como a recordação do evento traumático é na maioria dos casos extremamente fiel, rigorosa em seus detalhes, ela propicia acesso direto ao real. Assim sendo, Friedländer acredita que o Shoah, devido ao seu excesso, pode ser expresso sem distorção ou banalização. A extrema violência do Holocausto permitiu aos historiadores reorganizarem seu conhecimento sobre o real. Segundo o autor, como o excesso está além da capacidade que o indivíduo tem de imaginar e representar, como ele não tem limites e é irrepresentável, ele se revela (Friedländer, 1992). O que o indivíduo descreve não é uma construção de um evento vivenciado no passado, mas o próprio evento. Esta representação do real sem mediação está presente no testemunho de situações traumáticas. O testemunho de um "agora" é possível porque a consciência foi desativada.

Arquivos, testemunhos, depoimentos, registros são trazidos à tona com o objetivo de transmitir para futuras gerações o absurdo da violência desnecessária. O arquivo e memorial Yad Vashem, em Jerusalém, contém o maior número de informações sobre o Holocausto em todo o mundo, e desempenha ainda hoje um importante papel político nas denúncias e condenações de participantes do regime hitlerista. Diversos outros arquivos desempenham papel similar. O Conselho Internacional de Reabilitação de Vítimas de Tortura, em Copenhague, também guarda um importante conjunto de depoimentos e informações sobre violações aos direitos humanos ocorridas em guerras mais recentes, como as ocorridas na Bósnia, Afeganistão e Iraque. Em contraposição ao esquecimento, organizações se constituem para lutar contra o arbítrio através do trabalho de recuperar nomes e restaurar os fatos que podem ainda ser lembrados. O papel destes arquivos não é o de explicar o que não pode ser explicado, mas manter viva a memória do que não pode se repetir.

Chegamos à conclusão de que não há a decisão última em relação à memória. Mais uma vez, o esquecimento, em alguns casos, pode ser não só uma escolha, como também uma dádiva. Além disso, não obstante a excepcionalidade de situações traumáticas, não são poucos os autores que as identificam ao cotidiano da vida contemporânea. A descrição da experiência 
do choque por Walter Benjamin é uma das primeiras e mais fortes imagens do indivíduo moderno, fragmentado, incapaz de reagir aos estímulos com que se depara (Benjamin, 1973).

\section{A resposta da nova historiografia}

Nos últimos anos a historiografia contemporânea tem procurado responder à questão colocada por Georges Bataille. Historiadores ligados ao campo da história do tempo presente e sobretudo da história oral tem se preocupado em construir um espaço, no interior da narrativa histórica, de valorização da subjetividade, dos sentimentos e da experiência humana. Esta preocupação tem se traduzido, por um lado, no esforço constante de desvendar as mais sutis e camufladas relações de dominação entre os homens - estabelecidas, muitas vezes, a partir do próprio processo social de construção de memória(s); e, por outro, na intenção de resgatar memórias, experiências e vivências ocultadas e silenciadas. A nova historiografia dá voz àqueles que não aparecem no registro documental, proporcionando a recuperação da história dos grupos em pequena escala. Ela procura pelos relatos construídos ao longo do trajeto pessoal de cada indivíduo, os quais, embora parciais, têm profundidade e contornos morais ligados à subjetividade, elementos que escapam às demais análises (Thompson, 1992).

Michel Pollak, no texto "Memória, esquecimento, silêncio" (1989) chamou atenção para os processos de dominação e submissão das diferentes versões e memórias, apontando para a clivagem entre a memória oficial e dominante e "memórias subterrâneas", marcadas pelo silêncio, pelo não dito, pelo ressentimento. Esta clivagem pode aparecer não apenas nas relações entre um Estado dominador e a sociedade civil, como também entre a sociedade englobante e grupos minoritários. São lembranças "proibidas", "indizíveis" ou "vergonhosas" que muitas vezes se opõem à mais legítima e poderosa das memórias coletivas: a memória nacional.

Nesta direção são muito interessantes as pesquisas de Henri Rousso e de Alessandro Portelli. Rousso estudou os processos de "enquadramento" da memória nacional francesa - com suas operações de ocultamento e reconstrução política principalmente no que se refere à Segunda Grande Guerra, à Resistência e ao colaboracionismo. Rousso mostra como a Colaboração e o Governo de Vichy foram relegados à margem da memória nacional, esquecidos, e, mais do que isso, ocultados (Rousso, 1987).

Portelli, num texto bastante conhecido dos pesquisadores ligados à História Oral, estudou as diferentes "camadas" de memória sobre o massacre perpetrado por soldados alemães que se construíram na pequena cidade italiana de Civitella. Para o governo italiano Civitella aparecia como um 
símbolo da resistência ao fascismo. $\mathrm{O}$ aniversário do massacre era comemorado com honras nacionais. Mas Portelli descobriu, nos depoimentos dos moradores, uma memória subterrânea, oculta, muito diferente da memória oficial. Os moradores sobreviventes viam o massacre como conseqüência da irresponsabilidade de militantes partigiani que haviam matado alguns oficiais alemães e deixado a população exposta à vingança nazista. Mas esta memória local não cabia na memória oficial que exaltava o heró́smo da pequena vila e por isso era ocultada (Portelli, 1996).

Aos estudos de Rousso e Portelli se aplica perfeitamente o alerta do historiador francês, Pierre Ansart (2001): "É preciso considerar os rancores, as invejas, os desejos de vingança e os fantasmas da morte”. Ansart pretende incorporar à narrativa da história a sua parte "sombria, inquietante, freqüentemente terrificante". Baseando-se sobretudo em Nietzsche, Ansart propõe aos pesquisadores uma história dos ressentimentos, uma história que leve em conta, por exemplo, a experiência da humilhação e do medo como motores poderosos da ação e reação humanas.

Estes quatro autores lidam com o trauma político resultante de genocídios, ditaduras e tiranias. A nosso ver esse tema tem recebido importantes contribuições de pesquisadores ligados à História Oral, à história das mulheres e, numa abordagem interdisciplinar, à antropologia. Gostaríamos de comentar aqui alguns destes trabalhos - vários deles ainda em fase de pesquisa e elaboração de conclusões.

O primeiro trabalho que gostaríamos de analisar aqui é o de Silvia Salvatici, pesquisadora italiana que estuda, através de depoimentos orais de imigrantes, o impacto da violência na guerra do Kosovo. Dois textos seus foram publicados na Revista de História Oral: "Memórias de gênero: reflexões sobre a história oral de mulheres" e "Narrativas de violência no Kosovo do pós-guerra" (Salvatici, 2005a e 2005b). Nos dois trabalhos, altamente complementares, Silvia aponta para uma questão importante: o aporte novo e revelador trazido pelos depoimentos femininos para a construção da narrativa histórica. Silvia sublinha o fato de que o campo da história oral e o da história das mulheres se desenvolveram juntos e incentivando-se mutuamente. Ambos nasceram da preocupação de resgatar aquilo que não tinha registro histórico e que, na maioria das vezes, se apoiava apenas no testemunho e no depoimento oral para ser lembrado e conhecido. Tanto um campo quanto o outro teve a preocupação de resgatar esta "voz do passado"7 e dar-lhe um lugar na história. Para os pesquisadores da história oral e da história das mulheres esta era uma preocupação

7 A expressão é do historiador inglês Paul Thompson, 1992. 
política, militante. Mas quando estes dois campos se cruzaram efetivamente a história encontrou algo novo.

Em sua pesquisa empírica, Salvatici nos mostra toda a riqueza desta experiência marcada pela subjetividade feminina e por comportamentos e posturas de gênero, determinados pela situação de guerra. Ela reproduz os depoimentos de mulheres que estiveram em campos de concentração, que participaram de resistências, que viveram épocas de guerras civis, trazendo para a história todo um lado da experiência humana em tempos de guerra e arbítrio que era desconhecido e ocultado. Entram para a história episódios, experiências e vivências envolvendo estupros, partos clandestinos, abortos, os cuidados com doentes, a proteção das crianças, o armazenamento de comidas, a produção de vestimentas e até de disfarces, a improvisação para lidar com a fome e o frio em épocas de escassez severa. Outros depoimentos de mulheres relatam as experiências do amor clandestino, dos beijos trocados atrás de barricadas, dos casamentos apressados, das gestações solitárias, da alegria de partos realizados em precárias condições, mas bem sucedidos. A dimensão amorosa das atividades políticas em tempos de guerra pôde vir à tona a partir de relatos orais e depoimentos femininos. Enfim, uma gama de experiências e formas de enfrentamento de guerras e tiranias que não eram conhecidas, que não apareciam nos relatos e registros históricos, nem mesmo nos depoimentos de pessoas que tinham vivido essas situações. A maioria desses depoimentos era dada por homens a partir de experiências masculinas nas prisões, nos campos de concentração, e nos grupos de resistência. A experiência tipicamente feminina deste tipo de situação traumática só pôde aparecer com destaque a partir do cruzamento da história oral com a história de mulheres. E somente a partir disso, foi possível para nós pesquisadores trazer para a história uma dimensão da experiência e da vivência humana inteiramente ignorada porque alicerçada na subjetividade feminina, excluída da narrativa histórica.

Um outro historiador que traz questões importantes sobre a relação entre política e subjetividade é o sul-africano Jonathan Grossman. O texto "Violência e silêncio: reescrevendo o futuro", também publicado na Revista de História Oral traz à tona as dramáticas conseqüências de um processo político que tentou ignorar e, em alguns momentos, passar por cima das subjetividades dos atores envolvidos na história política da África do Sul. O texto de Grossman analisa o processo político de reconciliação e re-pactuação nacional vivido pelo país após o fim do regime de apartheid. Seu foco é explicitamente o trabalho da Comissão de Reconciliação e Verdade, que tinha por objetivo a reparação dos danos causados às vitimas e a valorização de uma política de Direitos Humanos (Grossman, 2000). 
O ponto levantado por Grossman é importante: a Comissão olhava para todas as pessoas que haviam sofrido nas mãos do regime - com prisões, torturas, clandestinidades, maus tratos, humilhações - como vítimas. E estas pessoas eram chamadas a depor e a relatar, diante da Comissão, o que haviam sofrido. Sem discordar da importância deste trabalho, Grossman chama a atenção para o fato de que inúmeras pessoas, sobretudo jovens, queriam depor na Comissão, mas não como vítimas. Queriam relatar seus feitos de luta, de resistência, de combate. Não se sentiam vítimas, mas, sim, heróis combatentes. E não havia lugar para eles; os seus depoimentos não eram desejados, nem registrados. A Comissão não buscava os heróis, mas sim as vítimas. Muitos destes jovens recusavam a vitimização, não se viam assim e nem queriam este lugar na história. Mas a Comissão de Reconciliação e Verdade não abria este espaço para eles, não estava interessada neste registro histórico.

Grossman chama a atenção para um processo político que "coloca o sofrimento antes e no lugar do envolvimento e da resistência política”:

$\mathrm{Na}$ medida em que somente a dor é focalizada, as pessoas que viveram toda uma experiência de sobrevivência e resistência acabam sendo reduzidas a simples vítimas, não sendo levado em conta o fato de que também são sobreviventes e resistentes. (2000: 19-20)

Havia, por parte destes jovens, uma recusa ao papel de vítima e o desejo de afirmar uma identidade ligada à idéia de resistência. Esta subjetividade, para Grossman, foi alijada do processo político pós-apartheid. E o alijamento desta subjetividade estaria alimentando fortes correntes de ressentimento na sociedade sul africana, chegando mesmo a comprometer, de forma perigosa, o sucesso do processo de reconciliação política.

Gostaríamos ainda de comentar a pertinência de um outro trabalho - agora no campo da antropologia - que discute as relações entre subjetividade e política. O livro de Kimberley Theidon, antropóloga da Universidade de Harvard, que há muitos anos estuda o Peru, tem o significativo titulo Entre Prójimos: el conflicto armado interno y la política de la reconciliación em el Peru (2004). O livro trata do conflito armado ocorrido no Peru, na década de 1980, resultante da atuação política do grupo extremista Sendero Luminoso. Baseia-se em um trabalho de campo realizado em Ayacucho, região onde ocorreu o maior número de vítimas do conflito armado peruano, a maior parte delas sendo indígenas. A pesquisadora estudou sete comunidades indígenas - que sofreram e infligiram sofrimento. $\mathrm{O}$ ponto de partida de Kimberley é o de que os habitantes das comunidades indígenas 
(e, algumas vezes as comunidades inteiras) se viam na contingência de se aliar ou com os senderistas ou com as Forças Armadas. E foi exatamente esta característica que conferiu ao conflito armado peruano - pelo menos na região de Ayacucho - a dimensão de guerra civil. Uma guerra que opunha os camponeses e índios ligados ao Sendero Luminoso de um lado, a camponeses e índios que apoiavam as Forças Armadas de outro. Camponeses e índios que, mobilizados pelos Sendero e pelos militares, lutavam entre si. A questão que Kimberley explora em seu prolongado trabalho de campo é a participação civil nas matanças e violências praticadas e sofridas pela população camponesa indígena.

¿Cómo es que las personas comenzaran a matarse entre prójimos? ¿Cómo militarizaron y desmilitarizaron la vida cotidiana y las subjetividades? (Theidon, 2004)

Esta é a questão colocada logo no prefácio do livro. Kimberley trabalha, especificamente, a questão da construção da subjetividade em tempos de guerra civil, a experiência de grupos sociais desamparados politicamente, manipulados por guerrilheiros e Forças Armadas, envolvendo-se em violentos conflitos com vizinhos, parentes e conhecidos. Desespero e política. É interessante colocar aqui neste texto o fato de que somente muito recentemente o conflito armado peruano - a guerra entre o Sendero e as Forças Armadas que teve lugar em Ayacucho - tem sido objeto de pesquisa histórica e social. Até há pouco tempo atrás este tema era um tabu intransponível. Somente agora os relatos sobre esta experiência têm aparecido e, mesmo assim, com muita dificuldade. Kimberley relata a enorme dificuldade que teve em obter depoimentos orais sobre a guerra. Camponeses e índios não queriam falar - nem muito menos registrar suas falas - sobre este assunto. Muito recentemente este tema também tem sido objeto da literatura peruana. O romance La hora azul de Alonso Cueto, já traduzido e publicado no Brasil (2006), é um bom exemplo disso. A sociedade peruana começa a rever, por variados caminhos, a história desta guerra.

Como foi uma história abafada e, em vários sentidos, clandestina, Kimberley aponta para a necessidade do manuseio de linguagens diversas no estudo deste tema. Entre estas linguagens ela aponta a linguagem do corpo: é necessário compreender uma experiência culturalmente informada pelo corpo, nos diz ela. A experiência de camponeses e índios nesta guerra civil foi marcada pelo corpo: dor física, torturas, pobreza e fome. O corpo, para ela, é um lugar de memória, um lócus onde se inscreveram experiências históricas importantes. 
A questão teórica e metodológica que Kimberley discute em seu trabalho é justamente a incorporação da construção da subjetividade nos estudos históricos e antropológicos - mas não apenas a valorização da subjetividade na narrativa histórica. Mais do que isso: ela propõe que a subjetividade seja incorporada como objeto e instrumento de pesquisa. Ela pretende chegar à investigação do corpo das pessoas (de seus depoentes) - de como esses corpos registram e relatam as experiências de medo, dor, humilhação e também esperança, alegria, alívio e gozo, ou seja, sentidos e emoções vividos numa guerra.

\section{Conclusão}

Ao longo deste artigo, foram destacadas abordagens que contribuíram de forma efetiva para a construção da noção que temos hoje do que seja história, memória e esquecimento. Mas, como nos diz o filósofo Edward Casey, o que quer que seja a memória ela excede o escopo da razão humana, resiste ser capturada na estrutura da intencionalidade. Quando se trata de produzir uma descrição exata da memória, é como se nós nos encontrássemos à deriva em confusões e esquecimentos lingüísticos comparáveis ao mar de Sargasso (Casey, 1987).

Frente a diversidade de abordagens e implicações políticas, procurou-se destacar que o problema que se coloca para pesquisadores que se voltam para o passado não está relacionado apenas à busca do conhecimento, pois envolve questões políticas e morais. ${ }^{8} \mathrm{~A}$ crítica de Michel Foucault à história como forma de estabelecer arbitrariamente uma origem, uma continuidade ou mesmo uma finalidade em função do poder deu lugar a um amplo debate sobre a relação entre conhecimento, moral e poder (Foucault, 1977). Inúmeros pesquisadores se voltam para a denúncia de narrativas que, embora revelem fatos e eventos do passado para gerações do presente, reproduzem dominações e formas de poder. As ditas objetividade e neutralidade de abordagens que procuram reconstituir o passado a partir dos métodos e rigores da ciência podem se constituir em novas formas de controle.

Em suma, a intenção de entrelaçar interpretações diversas sobre história, memória e esquecimento teve como objetivo mostrar que há várias formas de lidar com o passado e que todas elas envolvem interesse, poder e exclusões. A política da justa memória precisa se equilibrar entre a obsessão pelo passado e as tentativas de imposição do esquecimento.

A pesquisa relativa ao que aconteceu no passado - e o debate teórico e metodológico a ela relacionado - tem procurado, de variadas formas, res-

\footnotetext{
${ }_{8}^{8}$ Ver, entre outros, Seligmann-Silva, 2000.
} 
ponder aos limites da representação. Esperamos - e trabalhamos neste sentido - que novos caminhos sirvam para conhecermos melhor a nós mesmos, no sentido emancipatório e libertador deste conhecimento. Não se pode fazer uma história dos homens que ignore seja a subjetividade da condição humana, seja seus limites. Assim sendo, que o conhecimento desta subjetividade não sirva para a elaboração de meios mais eficazes de controle e dominação de uns homens sobre os outros - este tem sido o compromisso dos pesquisadores que trouxemos ao longo desta reflexão.

\section{Referências bibliográficas}

Ansart, Pierre (2001), "História e memória dos ressentimentos", in Stella Bresciani; Marcia Naxara (orgs.), Memória (res)sentimento: indagações sobre uma questão sensivel. São Paulo: Editora da Unicamp, 15-36.

Bataille, George (1995), "Concerning the Accounts Given by the Residents of Hiroshima”, in C. Caruth (org.), Trauma: Explorations in Memory. Baltimore: London, The John Hopkins University Press, 221-235.

Beck, Ulrich; Giddens, Anthony; Lash, Scott (1994), Reflexive Modernization: Politics, Tradition and Aesthetics in the Modern Social Order. Stanford, Ca.: Stanford UP. Benjamin, Walter (1968), "Thesis on the Philosophy of History", in Hannah Arendt (org.), Illuminations. New York: Harcourt Brace \& World, 253-264.

Benjamin, Walter (1973), Charles Baudelaire: A Lyric Poet in the Era of High Capitalism. London: NLB.

Casey, Edward S. (1987), Remembering: A Phenomenological Study. Bloomington: Indiana UP.

Cueto, Alonso (2006), A bora azul. Rio de Janeiro: Objetiva.

Davis, Natalie Zemon; Starn, Randolf (1989), "Introduction: Memory and Countermemory", Representations, 26, 1-6.

Foucault, Michel (1977), "Nietzsche, Genealogy, History", in M. Foucault, Language, Counter-memory, Practice. New York: Cornell UP, 139-164.

Freud, Sigmund (1955), "Beyond the Pleasure Principle", in James Strachey (org.), The Standard Edition of the Complete Psychological Works of Sigmund Freud. London: Hogarth Press, vol. 18, 3-64 [1920].

Friedländer, Saul (1992), Probing the Limits of Representation: Nazism and the 'Final Solution'. Cambridge, Mass.: Harvard UP.

Giddens, Anthony (1990), The Consequences of Modernity. Stanford: Ca.: Stanford UP.

Grossman, Jonathan (2000), "Violência e silêncio: Reescrevendo o futuro", História Oral, Revista da Associação Brasileira de História Oral, 3.

Halbwachs, Maurice (1925), Les cadres sociaux de la mémoire. Paris: Felix Alcan. 
Halbwachs, Maurice; Alexandre, J.H. (1950), La mémoire collective. Ouvrage posthume publié. Paris: PUF.

Koselleck, Reinhart (1985), Futures Past: On the Semantics of Historical Time. Cambridge, Mass.: MIT Press.

Lash, Scott (1998), 'Being After Time: Towards a Politics of Melancholy', in S. Lash; A. Quick; R.H. Roberts, Time and Value. Oxford, UK/Malden, Mass.: Blackwell, 147-161.

McNamara, Robert S. (1996), In Retrospect: The Tragedy and Lessons of Vietnam. New York: Vintage Books.

Middleton, David; Edwards, Derek (1990), Collective Remembering. London: Newbury Park / Ca.: Sage Publications.

Nora, Pierre (1984), Les lieux de mémoire. Paris: Gallimard.

Pollak, Michael (1989), "Memória, esquecimento e silêncio", Estudos Históricos, 3, 3-15.

Portelli, Alessandro (1996), "O Massacre de Civitella Val di Chiara (Toscana, 29 de junho de 1944): mito e política, luta e senso comum”, in Marieta de Moares Ferreira; Janaína Amado (orgs.), Usos e abusos da história oral. Rio de Janeiro: Editora Fundação Getúlio Vargas, 103-130.

Ricœur, Paul (2000), La mémoire, l'bistoire, l'oubli. Paris: Seuil.

Rousso, Henri (1987), La syndrome de Vichy. Paris: Seuil.

Salvatici, Silvia (2005a), "Memórias de gênero: reflexões sobre a história oral de mulheres”, História Oral, Revista da Associação Brasileira de História Oral, 8(1), 29-42.

Salvatici, Silvia. (2005b), "Narrativas de violência no Kosovo do pós-guerra”, História Oral, Revista da Associação Brasileira de História Oral, 8(1), 115-127.

Santos, Myrian Sepúlveda dos (1998), "Sobre a autonomia de novas identidades coletivas: Alguns problemas teóricos”, Revista Brasileira de Ciências Sociais, 13(38), 151-165.

Seligmann-Silva, Marcio (2000), “A História como Trauma”, in Catástrofe e Representação: ensaios. São Paulo: Escuta, 73-98.

Scheler, Max; Frings, M. S. (1994), Ressentiment. Milwaukee, Wis.: Marquette University Press.

Taussig, Michael T. (1986), Shamanism, Colonialism, and the Wild Man: A Study in Terror and Healing. Chicago: University of Chicago Press.

Theidon, Kimberley (2004), Entre Prójimos: el conflicto armado interno y la politica de la reconciliación en el Peru. Lima: IEP.

Thompson, Paul (1992), A voz do passado. Rio de Janeiro: Paz e Terra.

White, Hayden (1987), The Content of the Form: Narrative Discourse and Historical Representation. Baltimore: Johns Hopkins UP. 